\title{
Nursing Process in a Patient with Crohn's Disease: Case Report
}

\section{Jaqueline Ribeiro de Barros ${ }^{1 *}$, Giedre Soares Prates Herrerias', Madhoor Ramdeen ${ }^{2}$, Rogerio Saad-Hossne ${ }^{3}$, Rubia Aguiar Alencar4, Ligia Yukie Sassaki ${ }^{1}$}

\author{
${ }^{1}$ Department of Internal Medicine, São Paulo State University (Unesp), Medical School, Botucatu, Brazil \\ ${ }^{2}$ Department of Inflammatory Bowel Disease, St. Mark's Hospital, London, UK \\ ${ }^{3}$ Department of Surgery, São Paulo State University (Unesp), Medical School, Botucatu, Brazil \\ ${ }^{4}$ Department of Nursing, São Paulo State University (Unesp), Medical School, Botucatu, Brazil \\ Email: *jackbnurse@gmail.com
}

How to cite this paper: de Barros, J.R. Herrerias, G.S.P., Ramdeen, M., Saad-Hossne, R., Alencar, R.A. and Sassaki, L.Y. (2021) Nursing Process in a Patient with Crohn's Disease: Case Report. Open Journal of Nursing, 11, 258-265.

https://doi.org/10.4236/ojn.2021.114023

Received: March 24, 2021

Accepted: April 24, 2021

Published: April 27, 2021

Copyright (C) 2021 by author(s) and Scientific Research Publishing Inc. This work is licensed under the Creative Commons Attribution International License (CC BY 4.0).

http://creativecommons.org/licenses/by/4.0/

\begin{abstract}
Background: Inflammatory Bowel Disease is a term that covers intestinal diseases, including ulcerative colitis and Crohn's disease. Due to the condition of chronic and complex disease, the disease requires specialized nursing care and management in the context of a multi-disciplinary approach. As a guarantee of quality nursing care, it is essential to carry out the nursing process. Considering the commitment to assist the patient with Crohn's disease, the nurse, through the nursing consultation, is able to diagnose the patient's needs, proceed to the prescription of care and later evaluate the interventions, having the opportunity to develop work aimed at improving the quality of life of these patients. Objective: To describe the nursing process in a patient with Crohn's disease. Methods: Exploratory case report study, carried out at the outpatient clinic for inflammatory bowel diseases of a public hospital in the countryside of the state of São Paulo, from June 2019 to October 2019. Data collection was performed through anamnesis, physical examination and analysis of medical records. Results: Female patient, 34 years old, diagnosed with Crohn's disease. With the completion of the nursing process, it was possible to identify five nursing diagnoses and the elaboration of interventions and outcomes. The nursing evaluation was continuous and the patient adhered to the proposed interventions. Final considerations: The systematization and organization of the work of the nursing team proved to be essential for quality care, with efficiency and effectiveness, guaranteeing the patient comfort, general well-being and good rehabilitation.
\end{abstract}

\section{Keywords}

Nursing Care, Crohn's Disease, Nursing Process 


\section{Introduction}

Inflammatory Bowel Disease (IBD) is a term that covers intestinal diseases, including ulcerative colitis (UC) and Crohn's disease (CD). The most common symptoms are diarrhea, abdominal pain, anemia and fatigue [1]. The disease is a multifactorial cause, more prevalent in adulthood, from 20 to 40 years [1]. CD may affect any segment of the mouth to the anus and may present stenoising, penetrating or fistulizing behavior [1]. Extra-intestinal manifestations are also described, affecting the joints, skin, eyes and liver [1]. Diagnosis is confirmed by clinical, endoscopic evaluation and inflammatory markers and treatment may be clinical and/or surgical [1].

Due to the condition of chronic and complex disease, the disease requires specialized nursing care and management in the context of a multi-disciplinary approach [1]. As a guarantee of quality nursing care, it is essential to carry out the nursing process (NP) using scientific-technical knowledge in the health-disease process, covering the patient, family and community, in addition to guiding nursing care and contributing "to the health care of the population, increasing visibility and professional recognition" [2]. The NP is performed in five interrelated, interdependent and recurrent stages: nursing history, nursing diagnosis, nursing planning, nursing implementation and evaluation [2]. Moreover, it is also a methodological tool that should be developed intentionally by the nurse [3].

The use of care protocols in the care of patients with IBD is indispensable, because nursing care becomes systematized, complying with the Resolution of the Federal Nursing Council 358/2009 [2], that provides for the Systematization of Nursing Care and the implementation of the NP in environments, public or private, in which nursing professional care occurs. Thus, more effective results are expected with the standardization of actions and ensure more humanized assistance.

Considering the commitment to assist the patient with $\mathrm{CD}$, the nurse, through the nursing consultation, which must be based on theoretical reference, is able to diagnose the patient's needs, proceed to the prescription of care and later evaluate the interventions, having the opportunity to develop work aimed at improving the quality of life of these patients.

We chose to use the reference of Dorothea Orem's General Theory, also known as the Nursing Theory of Self-Care Deficit, composed of three interrelated theories: Self-care Theory, Self-Care Deficit Theory and Nursing Systems Theory [4], which aims to identify self-care deficits and observe the extent to which the patient is able to perform self-care, which is fundamental for maintaining the health of patients with CD. There is a scarcity of studies on NP in IBD, therefore, this case study aims to describe NP in patients with CD.

\section{Methods}

This is an exploratory case report of a patient with CD. The study was carried out in the IBD outpatient clinic of a public hospital in the countryside of the 
state of São Paulo, Brazil, from June 2019 to October 2019.

Data collection was performed through anamnesis, physical examination, medical analysis and questions to the health-disease process based on Dorothea Orem's Self-Care Theory [4]. Subsequently, the real and potential problems presented by the patient were identified and after careful analysis and interpretation of the data, the diagnoses were identified from the taxonomy of NANDA [5] and listed in order of priority, followed by the survey of nursing interventions and outcomes according to the NIC-Nursing Interventions Classification [6] and NOC-Nursing Outcomes Classification [7].

The study was approved by the Research Ethics Committee of the Botucatu Medical School under opinion number 3.383.455 (CAAE: 14023119.0.0000.5411). The subject invited to participate in this study was informed about the objective, expected results and participated after the consent and signing of the Free and Informed Consent Form.

\section{Results}

With the realization of the NP, it was possible to understand all steps of the process, which must be interrelated, interdependent and recurring. Table 1 presents the actions and practices developed and technologies or strategies used in each step of the process.

Next, the five steps of the NP are been presented with the details of each one.

\subsection{Nursing History}

In the first stage of the NP, the investigation was carried out through the patient giving a thorough account of their medical history, family and community history as well as physical assessment. Sociodemographic data: female patient, 34 years old, white, incomplete higher education, administrative assistant, married, without children, lives with her husband in the urban area of the city in the countryside of the state of São Paulo, sedentary, non-smoking, non-alcoholic. History of current disease: CD Ileo-colonic with perianal fistulae and anal canal stenosis, diagnosed in 2005. She started treatment with azathioprine associated

Table 1. Steps in the nursing process and technologies or strategies used.

\begin{tabular}{|c|c|c|}
\hline Moment & Steps & Technologies or strategies \\
\hline \multirow{5}{*}{$\begin{array}{l}\text { Outpatient care at } \\
\text { the Inflammatory } \\
\text { Bowel Disease } \\
\text { Clinic }\end{array}$} & Nursing History & Data with the patient and in electronic medical records \\
\hline & Nursing Diagnoses & Identified from the NANDA taxonomy \\
\hline & Nursing Planning & $\begin{array}{l}\text { Nursing interventions and oucomes were identified } \\
\text { according to the Nursing Interventions Classification } \\
\text { (NIC) and Nursing Outcomes Classification (NOC) }\end{array}$ \\
\hline & Implementation & $\begin{array}{l}\text { Observation of positive behaviors and feedback from the } \\
\text { patient }\end{array}$ \\
\hline & Nursing Evaluation & Continuous by the nurse \\
\hline
\end{tabular}


with infliximab, and infliximab was suspended due to a late reaction characterized by a cutaneous rash in 2010 . On that time she started the use of subcutaneous adalimumab $40 \mathrm{mg}$ every 2 weeks, which was suspended in 2018 due to therapeutic failure. In 2014 and 2015, the patient underwent perianal fistulae curettage, abscess drainage and anal canal dilations with Hegar candles for the treatment of anal canal stenosis. In June 2018, azathioprine was discontinued and the patient started treatment with vedolizumab due to moderate disease activity and refractory to the use of anti-TNF, but without clinical response. She was hospitalized in September 2018 with severe abdominal pain, lack of appetite, diarrhea with blood and loss of $19 \%$ of body weight, characterizing malnutrition and starting nutritional therapy. The patient underwent segmental enterectomy and ileostomy due to complications of the disease and received parenteral nutrition during this period. She was discharged from the hospital after 34 days of hospitalization, with improved food acceptance and weight recovery. She started treatment with ustekinumab to prevent postoperative recurrence of $\mathrm{CD}$, and underwent intestinal transit reconstruction in July 2019. Currently continues to be treated clinically with ustekinumab $90 \mathrm{mg}$ subcutaneous ly every 8 weeks with good clinical and endoscopic response.

Personal history: no important personal history.

Family history: brother with CD Ileal since December 2009.

Current clinical diagnosis: CD Ileo-colonic with perianal fistulae and anal canal stenosis since 2005.

Health needs: vaccines were administered according to the national immunization program. The last preventive examination of the cervix was performed in June 2019 with absence of malignancy. Allergic to sulfasalazine, irregular use of daily sunscreen, preserved sleep and diet as directed by the nutritionist. It presents autonomy for self-application of subcutaneous medication, good adherence to the prescribed therapeutic regimen.

Biopsychosocial and sexual needs: practicing catholic. Active sex life and dyspareunia occasionally, regular menstruation, denies use of contraceptive method. Good acceptance of the disease, self-esteem preserved with self-acceptance and independence verbalizations in the decision-making process, ability to perform self-care in relation to food, activities of daily living and personal hygiene and maintain leisure hours.

Physical examination: height: $167 \mathrm{~cm}$, weight: $64 \mathrm{~kg}$. Vital signs: pulse rate: 65 bpm, respiratory rate: $18 \mathrm{bpm}$, blood pressure $110 \times 60 \mathrm{~mm} \mathrm{Hg}$ and temperature: $36.4^{\circ} \mathrm{C}$. Neurological system: conscious, oriented. Hydration: flushed, hydrated. Skin, head, eyes/vision, ears/hearing, nose, mouth and throat, neck, chest, pulmonary auscultation, cardiac auscultation, pulse/heart rhythm: no changes. Abdomen: flaccid, flat, air-fluid noise present, tympanic, normotensive, absence of palpable mass, scar in the mesogastric region (surgical wound) and right flank (ileostomy). Ends: No changes. Perianal disease is in remission. Evacuation present, pasty feces, without pathological products, 3 to 4 times a day and diuresis present, without alterations. 


\subsection{Diagnoses and Nursing Planning}

Five main nursing diagnoses were identified from the survey of the history and consequently the interventions that are part of nursing planning and outcomes (Table 2).

\subsection{Implementation}

After the interventions, the patient presented positive conducts and feedback, further strengthening and a relationship of trust with the multidisciplinary team.

\subsection{Nursing Evaluation}

The nursing evaluation was continuous and the patient adhered to the proposed nursing interventions with great enthusiasm, favoring the achievement of the expected results.

\section{Discussion}

It is believed that to face the challenges of caring for people with chronic diseases, it is necessary to identify factors that can influence people to become more

Table 2. Main nursing diagnoses, interventions and results.

\begin{tabular}{|c|c|c|}
\hline Nursing Diagnoses & Nursing Planning & Nursing Outcomes \\
\hline $\begin{array}{l}\text { Willingness to literacy in } \\
\text { improved health characterized } \\
\text { by the desire to increase } \\
\text { knowledge about current } \\
\text { health determinants in social } \\
\text { and physical environments. }\end{array}$ & $\begin{array}{l}\text { - Determine the personal context and sociocultural history of the healthy } \\
\text { behavior of the individual, family or community. } \\
\text { - Prioritize the learning needs identified based on client preference, nurse } \\
\text { skills, available resources and probability of achieving the goal successfully. } \\
\text { - Emphasize the immediate or short-term positive health benefits to be } \\
\text { received by a positive life behavior rather than long-term benefits or } \\
\text { negative effects of non-acceptance. }\end{array}$ & $\begin{array}{l}\text { - Knowledge: health behavior } \\
\text { - Knowledge: health } \\
\text { promotion } \\
\text { - Willingness for improved } \\
\text { knowledge }\end{array}$ \\
\hline $\begin{array}{l}\text { Willingness to control } \\
\text { improved health } \\
\text { characterized by the desire } \\
\text { to improve the control of } \\
\text { risk factors and symptoms. }\end{array}$ & $\begin{array}{l}\text { - Monitor bowel movements, including frequency, consistency, shape, volume, } \\
\text { and color, as appropriate. } \\
\text { - Monitor the occurrence of signs and symptoms of diarrhea, constipation and } \\
\text { impaction. } \\
\text { - Teach patients the proper use of antidiarrheal medications. }\end{array}$ & $\begin{array}{l}\text { - Knowledge: control of } \\
\text { Inflammatory Bowel Disease } \\
\text { - Pain control } \\
\text { - } \text { Symptom control }\end{array}$ \\
\hline $\begin{array}{l}\text { Risk of chronic functional } \\
\text { constipation associated with } \\
\text { inflammatory bowel disease } \\
\text { and anal stenosis. }\end{array}$ & $\begin{array}{l}\text { - Explain etiology of the problem and justification for actions to the patient. } \\
\text { - Guide patient/family on the relationship between diet, exercise and fluid } \\
\text { intake for constipation/impaction. } \\
\text { - Guide the patient on specific foods that help promote intestinal regularity. }\end{array}$ & $\begin{array}{l}\text { - Intestinal elimination } \\
\text { - Intestinal continence } \\
\text { - Risk detection }\end{array}$ \\
\hline $\begin{array}{l}\text { Willingness to improved } \\
\text { self-concept characterized by } \\
\text { confidence in abilities, } \\
\text { satisfaction with thoughts } \\
\text { about oneself and with a } \\
\text { sense of appreciation. }\end{array}$ & $\begin{array}{l}\text { - Encourage the patient to assume the utmost responsibility for self-care. } \\
\text { - Provide positive feedback for acceptance of additional liability and/or } \\
\text { behavior change. } \\
\text { - Encourage the patient to identify strengths. }\end{array}$ & $\begin{array}{l}\text { - Acceptance: state of health } \\
\text { - Self-Esteem } \\
\text { - Quality of life }\end{array}$ \\
\hline
\end{tabular}

Source: The author, 2020. 
involved in self-care and also in the empowerment of knowledge about the diagnosis and management of the disease, through education [8]. The first nursing diagnosis identified refers to this concept, expanding the knowledge of the disease allowing the patient to master the subject and the decision shared with the health team, aiming at favorable outcomes that reflect on the improvement of quality of life and the positive experience of self-care. In addition, social support can facilitate coping with the disease on the state of health [1], corroborating the results of the present study.

Patient empowerment includes gaining knowledge about risk factors and identifying symptoms [9], criteria that make up the second nursing diagnosis, favoring decision-making aimed primarily at the remission of the disease.

The third nursing diagnosis refers to the identification of nutritional needs and referral to the nutritionist, when necessary [1]. Nurses need to familiarize themselves with the nutritional diagnosis and interventions indicated in order to provide the appropriate diet for each patient [10], especially in specific situations such as stenosaning disease and in the post-surgical period.

The fourth diagnosis refers to the symptom of constipation associated with IBD and secondary to canal shading. Patients with IBD may present slowing of intestinal transit for several reasons: use of medications, presence of inflammatory process, changes in diet for symptom management, decreased food intake, less mobility, difficulty evacuating due to the presence of fistula and perianal abscess, presence of anal canal stenosis, among other causes. The multidisciplinary team should be able to recognize the symptom, adequately assess risk factors, and adequately manage constipation [11]. The proposed interventions are in line with the literature [1].

IBD affects all aspects of everyday life and the stress caused by the disease can cause exacerbation of symptoms and disease activity itself [12]. In a previous study with 109 patientes with IBD in clinical and endoscopic remission, Mancina et al. [13] showed that gastrointestinal symptoms are determinant for psychological alterations such as anxiety, depression, fatigue and sleep disorders and also in the participation of social and physical activities; therefore, proper management of psychological aspects is expected to improve resilience and favor the development of coping strategies [12]. The fifth diagnosis refers to self-care, confidence in abilities, satisfaction with thoughts about oneself and a sense of appreciation.

A systematic review performed by Spagnuolo et al. [14] showed the evaluated nursing activity through outcomes that are affected, provided, and/or influenced by nurses and defined as nursing-sensitive outcomes in adult IBD patients, where the domains identified were health care; psychological status, quality of life, patient knowledge, patient satisfaction; disease status, safety, and our study identified that the most of domains revealing similarity with the nursing practices performed.

Nursing interventions should encourage the patient to assume self-care, leading to reduction of costs with treatment, learning skills to solve problems and 
strengthening support for the search for better quality of life.

The challenges for nursing care in patients with IBD begin in the knowledge about the disease, favoring evidence-based judgment and management and this work contributes to the dissemination of knowledge and growth of research with the theme so little described in the literature.

\section{Final Considerations}

The study allowed the elaboration and dissemination of NP in patients with CD, in addition, the use of Orem's Theory made it possible to identify aspects of self-care, indispensable to individuals with $\mathrm{CD}$ in their daily lives, with the intention of ensuring development for the benefit of life, health and well-being.

Despite some limitations such as incomplete data in the medical records, the case study demonstrates the potential and commitment of nursing practice to contribute to the construction of new studies on this theme. Nurses who care for patients with IBD develop highly specialized and complex care. The systematization and organization of the work of the nursing team are essential for quality, efficient and effective care, which guarantees comfort, general well-being and good rehabilitation to the patient and, in addition, allows the performance of the NP with satisfaction and success.

\section{Funding Sources}

This work was supported by the Coordination for the Improvement of Higher Education Personnel-Brazil (CAPES)—Finance Code 001.

\section{Author's Contribution}

As the corresponding author, I attest that all authors have contributed substantially to the paper and take responsibility for its contents. Jaqueline Ribeiro de Barros and Ligia Yukie Sassaki contributed to the conception and design of the study, acquisition, analysis and interpretation of data, drafting the article, revising it critically for important intellectual content and final approval of the version to be submitted. Giedre Soares Prates Herrerias, Rogerio Saad-Hossne and Rubia Aguiar Alencar contributed to the acquisition, analysis and interpretation of data and revising it critically for important intellectual content. Madhoor Ramdeen revised it critically for important intellectual content. All authors have approved the final version submitted for publication and agreed to all aspects of work ensuring integrity and accuracy.

\section{Acknowledgements}

We thank CAPES for the post-graduation scholarship offered to Jaqueline Ribeiro de Barros.

\section{Conflicts of Interest}

The authors declare no conflict of interest. 


\section{References}

[1] Kemp, K., Dibley, L., Chauhan, U., Greveson, K., Jäghult, S., Ashton, K., et al. (2018) Second N-ECCO Consensus Statements on the European Nursing Roles in Caring for Patients with Crohn's Disease or Ulcerative Colitis. Journal of Crohn's and Colitis, 12, 760-776. https://doi.org/10.1093/ecco-jcc/jjy020

[2] Federal Nursing Council (2009) http://www.cofen.gov.br/resoluo-cofen-3582009_4384.html

[3] Silva, J.P., Garanhani, M.L. and Peres, A.M. (2015) Systematization of Nursing Care in Undergraduate Training: The Perspective of Complex Thinking. Revista LatinoAmericana de Enfermagem, 23, 59-66. https://doi.org/10.1590/0104-1169.0096.2525

[4] Orem, D.E. (1995) Nursing: Concepts of Practice. Mosby, St. Louis.

[5] Herdman, T.H. and Kamitsuru, S. (2018) Nursing Diagnones: Definitions and Classification 2018-2020/[NANDA International]; Translation: Regina Machado Garcez. Artmed, Porto Alegre.

[6] Bulechek, G.M., Butcher, H.K., Dochterman, J.M. and Wagner, C.M. (2016) Nursing Interventions Classification (NIC); Translation: Denise Costa Rodrigues. Elsevier, Rio de Janeiro.

[7] Moordhead, S., Johnson, M., Maas, M.L. and Swanson, E. (2016) Nursing Outcomes Classification (NOC): Measurement of Health Results; Translation: Alcir Fernandes, Carla Pecegueiro do Amaral, Eliseanne Nopper. Elsevier, Rio de Janeiro.

[8] Mullin, C., Griffiths, K. and White, L. (2019) The Newly Diagnosed Patient. In: Sturm, A. and White, L., Eds., Inflammatory Bowel Disease Nursing Manual, Springer, Switzerland, 217-223. https://doi.org/10.1007/978-3-319-75022-4_23

[9] Chauhan, U. (2019) Clinics. In: Sturm, A. and White, L., Eds., Inflammatory Bowel Disease Nursing Manual, Springer, Switzerland, 453-462. https://doi.org/10.1007/978-3-319-75022-4_48

[10] Vokes, L. (2019) Dietary Management. In: Sturm, A. and White, L., Eds., Inflammatory Bowel Disease Nursing Manual, Springer, Switzerland, 269-283.

https://doi.org/10.1007/978-3-319-75022-4_29

[11] Atkinson, N.S.S. (2019) Constipation. In: Sturm, A. and White, L., Eds., Inflammatory Bowel Disease Nursing Manual, Springer, Switzerland, 311-325. https://doi.org/10.1007/978-3-319-75022-4_33

[12] Inspector, Y. and Tyrrell, T. (2019) Stress and Psychological Support. In: Sturm, A. and White, L., Eds., Inflammatory Bowel Disease Nursing Manual, Springer, Switzerland, 345-354. https://doi.org/10.1007/978-3-319-75022-4_36

[13] Mancina, R.M., Pagnotta, R., Pagliuso, C., Albi, V., Bruno, D., Garieri, P., Doldo, P. and Spagnuolo, R. (2020) Gastrointestinal Symptoms of and Psychosocial Changes in Inflammatory Bowel Disease: A Nursing-Led Cross-Sectional Study of Patients in Clinical Remission. Medicina, 56, 45. https://doi.org/10.3390/medicina56010045

[14] Spagnuolo, R., Corea, A., Napolitano, D., Nisticò, E., Pagnotta, R., Pagliuso, C., Schiavoni, E., Turchini, L., Fiorino, G., Radice, S., Armuzzi, A. and Doldo, P. (2021) Nursing-Sensitive Outcomes in Adult Inflammatory Bowel Disease: A Systematic Review. Journal of Advanced Nursing, 77, 2248-2266. https://doi.org/10.1111/jan.14744 